\title{
Radius Distal Uç Kırığı Geçiren 45 Yaș Üzeri Hastalarda Osteoporoz ve Subklinik Vertebral Kırık Varlığı
}

\author{
The Presence of Osteoporosis and Subclinical Vertebral Fracture in Patients \\ Over 45 Years of Age With a Fracture of the Distal and of the Radius
}

\author{
Banu DILEK, Meltem BAYDAR, Ebru ŞAHIN, Burcu UZ, Özlem EL, Metin MANISALI*, Sema ÖNCEL \\ Dokuz Eylül Üniversitesi Tıp Fakültesi, Fiziksel Tip ve Rehabilitasyon Anabilim Dalı, Izmir, Türkiye \\ ${ }^{*}$ Dokuz Eylül Üniversitesi Tıp Fakültesi, Radyodiagnostik Anabilim Dalı, Izmir, Türkiye
}

\section{Özet}

Amaç: Bu çalışmanın amacı; Radius Distal Uç Kırı̆ı̆ı (RDUK) geçiren hastalarda osteoporoz ve Subklinik Vertebral Kırık (SVK) varlığının araştııımasıdır. Gereç ve Yöntem: Çalışmaya 45 yaş üstü, düşük enerjili travma sonrası RDUK gelişimi nedeni ile başvuran ve RDUK sonrası osteoporoz açısından değerlendirilmemiş hastalar alındı. Hastaların European Vertebral Osteoporosis Study (EVOS) anketine göre kalsiyum alımları ve fiziksel aktivite düzeyleri sorgulandı. Dual Enerji X-ray Absorbsiyometri (DXA) ölçümleri, SVK açısından lomber ve dorsal vertebra grafileri çekildi. Vertebra yükseklik kayıpları Genant sınıflamasına göre değerlendirildi. Sekonder osteoporoz nedenlerini belirlemek amacıyla biyokimyasal testler bakıldı.

Bulgular: Çalışmaya alınan 42 hastanın yaş ortalaması 59,26 $\pm 9,19$ yıl, vücut kitle indeksleri ortalaması $26,33 \pm 3,21 \mathrm{~kg} / \mathrm{m}^{2}$, RDUK sonrası geçen süre ise $15,11 \pm 16,07$ aydı. İstenen DXA tetkiki sonucunda hastaların 21 (\%50)'inde osteoporoz ve Genant'a göre hastaların $14(\% 33,3)$ 'ünde de SVK saptandı. Ortalama kırık sayısı 0,82 $\pm 1,33(0-4)$ ve kırık derecesi ise evre 1 düzeyinde değerlendirildi. Hastaların ortalama fiziksel aktivite skoru $12,43 \pm 5,31$ kalsiyum skoru 9,65 $\pm 3,34$ bulundu. DXA'da osteoporozu olmayan ancak SVK saptanan hasta oranı \%11,9 (5) olarak bulundu. SVK olan ve olmayan hastalar karşılaştırıldığında demografik özellikler ve biyokimyasal belirteçler açısından anlamlı fark bulunmadı.

Sonuç: RDUK'lar osteoporoza bağlı sık kırıklardandır ve morbiditesi ve mortalitesi daha yüksek olan kalça ve vertebra kırıklarının habercisi olarak kabul edilirler. RDUK geçiren hastalarda DXA ile osteoporoz saptanmasa da SVK mevcut olabilir.Türk Fiz Tıp Rehab Derg 2012;58:220-4.

Anahtar Kelimeler: Radius distal uç kırığı; subklinik vertebral kırık; osteoporoz
Summary

Objective: The purpose of this study was to research the presence of osteoporosis and Subclinical Vertebral Fracture (SVF) in patients with a fracture of the distal end of the radius (FDER).

Metarials and Methods: The patients over 45 years of age who presented with a FDER following a trauma and not evaluated for osteoporosis after FDER were included in the study. Calcium intake of the subjects was assessed using the European Vertebral Osteoporosis Study (EVOS) Questionnaire and the physical activity level was evaluated. Dual Energy X-ray Absorptiometry (DXA) measurements and thoracic and lumbar spine radiographs were performed for detecting SVF. Vertebral height loss was assessed according to Genant's classification. In order to determine the secondary causes of osteoporosis, biochemical tests were done.

Results: The average age of 42 patients included in the study was $59.26 \pm 9.19$; and the average body mass index was $26.33 \pm 3.21 .21$ patients were diagnosed as having osteoporosis and 14 patients were detected to have SVF. The average number of the fractures was $0.82 \pm 1.33(0-4)$ and the fracture grade was 1 . The average score of physical activities was found to be $12.43 \pm 5.31$ and the calcium score was $9.65 \pm 3.34$. The rate of patients who did not have osteoporosis according to DXA, however demonstrated SVF was reported to be $11.9 \%$. When the patients with and without SVF were compared, no significant difference was not found with regard to demographical characteristics and biochemical indicators.

Conclusion: FDERs are frequent osteoporotic fractures and are also accepted as a predictor of hip and vertebral fractures associated with higher level of morbidity and mortality. SVF may be present in patients with FDER even if the diagnosis of osteoporosis is not established by DXA. Turk J Phys Med Rehab 2012;58:220-4.

Key Words: Fracture of the distal end of the radius; subclinical vertebral fracture; osteoporosis 


\section{Giriş}

Osteoporoz, düşük kemik kütlesi, kemik mikromimarisinin bozulması, kemiğin kırılganlığında artma ve sonuçta kırık riskinin artması ile karakterize bir hastalıktır (1). Osteoporoz ve osteoporotik kırıklar günümüzde yaşam süresinin uzamasıyla birlikte morbiditesi, mortalitesi ve maliyeti açısından önemli bir sağlık sorunu haline gelmiştir (2).

Kalça ve vertebra kırıkları yüksek mortalite ve morbidite ile seyrettiğinden daha ön planda olmasına rağmen, Radius Distal Uç Kırıkları (RDUK) da osteoporoza bağlı yaygın görülen kırıklardır ve gelişecek diğer kırıkların, özellikle vertebra ve kalça kırıklarının habercisi olarak kabul edilirler (3). Erkeklerde RDUK'larının benzer yaştaki kadınlara göre vertebral kırık oluşturma riski benzer olmasına rağmen, mutlak kalça kırığı riskinin daha fazla olduğu bildirilmiştir. Bu nedenle RDUK'un beyaz erkeklerde iskelet frajilitesinin erken ve hassas bir belirleyicisi olduğu gösterilmiştir (4).

Kemik mineral yoğunluğu ile RDUK arasındaki ilişki birçok çalışmada gösterilmiştir (5-8). Düşük enerjili travma sonucu RDUK gelişen bir grup hastanın alındığı bir çalışmada, osteoporoz insidansı araştırılmış ve hastaların \%68'inde osteoporoz saptandığı bildirilmiştir (9). Hastaneye başvuran RDUK gelişen postmenopozal kadınların alındığı bir çalışmada ise bu hastaların önemli bir kısmının osteoporoz açısından yeterince değerlendirilmediği ve tedavi edilmediği gözlenmiştir (3).

Düşük enerjili kırıklar sonrasında gelişebilecek diğer kırıkların önlenmesi açısından bu kişilerde osteoporoz tanı ve tedavisi önem taşımaktadır. Vertebral kırıklar çoğu kez asemptomatiktir. Bir vertebral kırık oluşumu kemik mineral yoğunluğundan bağımsız olarak yeni vertebral kırık gelişme riskini 4-5 kat arttırmaktadır (10). Bu nedenle kırık riski taşıyan kişilerin belirlenmesi kırık oluşmadan koruyucu tedavi imkanı sağlamaktadır.

$\mathrm{Bu}$ çalışmanın amacı; düşük enerjili RDUK geçiren hastalarımızda; osteoporoz ve subklinik vertebral kırık (SVK) varlığını araştırmaktır.

\section{Gereç ve Yöntem}

Çalışmaya Eylül 2008 - Haziran 2010 tarihleri arasında Dokuz Eylül Üniversitesi Tıp Fakültesi Fiziksel Tıp ve Rehabilitasyon Anabilim Dalı polikliniğine düşük enerjili RDUK sonrası başvuran veya özgeçmişinde düşük enerjili RDUK olup osteoporoz açısından değerlendirilmemiş 45 yaş üzerinde 42 hasta alındı. Belirgin travma sonrası veya malignite nedeniyle patolojik kırık gelişen ve 45 yaş altı hastalar ile osteoporoz tanı ve tedavisi alan kişiler çalışmadan dışlandı. Hastalar dışlanma ve dahil edilme kriterlerine göre seçilip, onayları alındı. Daha sonra yaş, meslek, RDUK geçirdikleri tarih, vücut ağırlıkları, osteoporoz risk faktörleri ile European Vertebral Osteoporosis Study (EVOS) anketine göre kalsiyum alımları ve fiziksel aktivite düzeyleri sorgulandı. Bu ankette fiziksel aktivite skoru; ev dışında günlük yürüme süresi (4 puan skalası; 0: Hiç, 1: yarım saatten az, 2: 1/2-1 saat, 3: 1 saatten fazla), genç erişkin dönemi ve erişkin dönemde ayrı ayrı günlük fiziksel aktivite düzeyi (4 puan skalası; 1: hafif, 2: orta, 3: ağır, 4: çok ağır) ve yine genç erişkin ve erişkin dönemde ayrı ayrı spor yapma sıklığı (5 puan skalası; 0: Hiç , 1: Ara sıra, 2: Haftada bir saatten az, 3: Haftada 1-2 saat, 4: Haftada bir saatten fazla) üzerinden hesaplandı (Maksimum total aktivite skoru: 27 puan minimun aktivite skoru: 1) Yaşam boyu total kalsiyum alımı erişkin ve çocukluk döneminde süt ve süt ürünlerini tüketme sıkıkları (4 puanlı değerlendirme sistemi ile sistemi ile 1: haftada 1'den az, 2: her hafta, 3: her gün, 4: günde 1'den daha sık) toplanarak yaşam boyu total kalsiyum alım skoru elde edildi $(25,26)$. Ayrıca hastalarda kronik hastalık varlığı (hipertansiyon, diabet, koroner arter hastalığı, kronik böbrek yetmezliği, astım ve romatizmal hastalık) ve kemiğe etkili ilaç kullanımı (1. Steroid 2. immunosüpresif 3. Antiepileptik 4. Antiasit 5. Anksiyolitik 6. Tiroid hormonu 7. Antikoagulan 8. Tamoksifen 9. insülin 10. Diüretik 11. Statin) olup olmadığı sorgulandı. Hastaların sigara kullanımı 1) hiç kullanmadım, 2) eskiden kullandım en az bir yıl önce bıraktım.. paket/yıl içtim, 3) halen kullanıyorum...paket/ yıl içiyorum şeklinde üç başlıkta sorgulandı. Alkol kullanımı 1) 3 kadeh/günden fazla 2) yok şeklinde, güneşlenme ise mayo ile güneşlenme 1) var 2) yok şeklinde sorgulandı. Hastalara RDUK geçirdikten sonra acil servisten sonra Dual Enerji X-ray Absorbsiyometri (DXA) çekimi önerilip önerilmediği de soruldu.

Hastaların DXA ölçümleri LUNAR DPX-NT cihazı ile yapıldı. SVK riski açısından iki yönlü lumbosakral ve dorsal vertebra grafileri çekildi. Vertebra yükseklik kayıpları Genant sınıflamasına göre değerlendirildi. Genant ve ark. (27)’nın geliştirdikleri yöntemde T4 ile L4 arasındaki vertebra cisimleri alınmıştır. Vertebra cisminde değişiklik yoksa normal ya da Grade 0, vertebra cisim yüksekliğinde \%20-25 azalma varsa Grade 1, \%2640 oranında azalma varsa Grade 2, ve \%40'tan fazla azalma varsa Grade 3 olarak değerlendirilmiştir. DXA'da L1-L4, femur boyun ve toplam değerlerinden birinde T-skorunda $-2,5$ ve altında değeri olan hastalar osteoporoz tanısı aldı. Sekonder osteoporozu ayırt etmek ve kırık gelişiminde etkili faktörleri belirlemek amacıyla serumda $25(\mathrm{OH}) \mathrm{D}_{3}$ vitamini, tiroid fonksiyon testleri, açlık kan şekeri, serum parathormon, kalsiyum, fosfor ve alkalen fosfataz, osteokalsin, homosistein, vitamin B12 ve folik asit ile spot idrarda deoksipridinolin düzeyi ve 24 saatlik idrarda kalsiyum ve kreatinin düzeyi bakıldı.

Verilerin istatistiksel analizi Windows SPSS 15.0 programı ile yapıldı. Veriler ortalama \pm standart sapma ve yüzde olarak verildi. Verilerin normal dağılıma uygunluğu analiz edildi. Olgular osteoporozu olan ve olmayan ve subklinik vertebral kırığı olan ve olmayan olarak iki gruba ayrılarak veri analizi için kategorik veriler için ki kare testi, grup karşılaştırmaları için normal dağılıma uyanlarda t testi, uymayanlarda nonparametrik test ve Pearson ve Spearman korelasyon testi kullanıldı. Verilerin normal dağılıma uygunluğu analiz edildiğinde sadece lomber BMD'nin normal dağılıma uymadığı görüldü ve lomber BMD değerleri nonparametrik testlerle analiz edildi. İstatistiksel anlamlılık $\mathrm{p}<0,05$ olarak kabul edildi. 


\section{Bulgular}

Çalışmaya alınan 42 hastanın (11 erkek, 31 kadın) yaş ortalaması 59,26 $\pm 9,19$ yıl, vücut kitle indeksleri ortalaması $26,33 \pm 3,21 \mathrm{~kg} / \mathrm{m}^{2}$, RDUK sonrası geçen süre ise $15,11 \pm 16,07$ aydı. Altmış beş yaş üzeri hasta oranı \%28,6 (12) idi. Hastaların \%50 (21)'sinde DXA'ya göre osteoporoz, \%35,7 (15)'sinde osteopeni, \%14,3 (6)'ünde ise normal değerler saptandı. SVK oranı deneyimli radyolog tarafından yapılan ölçümler sonucunda, Genant radyolojik değerlendirme sistemine göre \%33,3 (14) olarak saptandı ve SVK derecesi ise evre 1 düzeyindeydi (Resim 1).

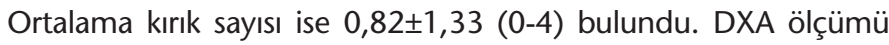
osteopenik değerlendirilen ancak SVK saptanan hasta oranı $\% 11,9$ (5) olarak bulundu. Altmış beş yaş ve üzeri hasta grubunun \%45,5 (5)'inde SVK saptanırken, 65 yaş altı hasta grubunda \%30 (9) oranında saptandı. Kronik hastalığı olanların \%41,7 (10)'sinde SVK saptanırken, kronik hastalığı olmayanların \%23,5 (4)'inde SVK saptandı. Hastaların EVOS anketine göre ortalama fiziksel aktivite

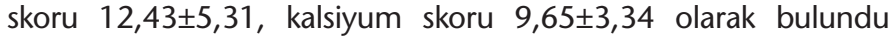

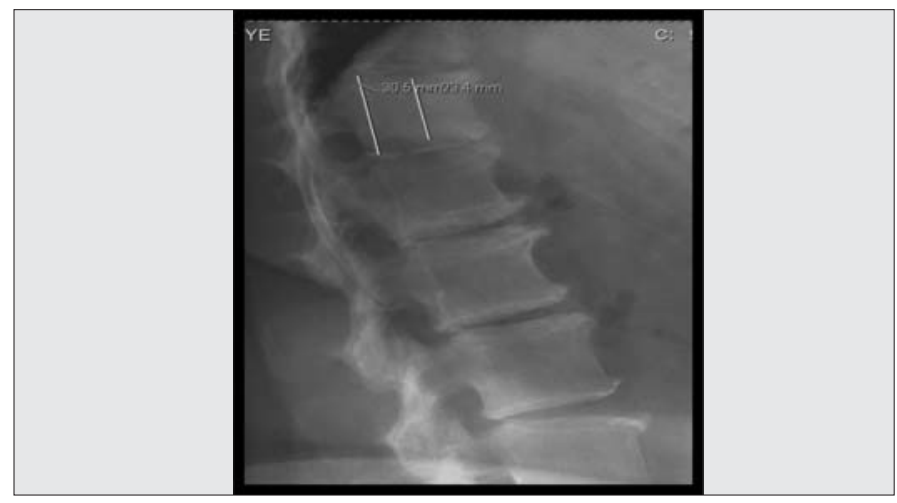

Resim 1. Bir hastada lateral lomber grafide yükseklik kaybı.
(Tablo 1). SVK varlığı ile yaş grubu, kronik hastalık, kemiğe etkili ilaç kullanımı, başka kırık geçirmiş olmak, sigara, alkol kullanımı, yürüyüş yapmak, güneşlenme, vejeteryan beslenme ve DXA'da osteoporoz varlığı arasındaki ilişki değerlendirildi ve istatistiksel anlamlılık saptanmadı ( $p>0,05)$. Ancak yaşla birlikte SVK sayısında anlamlı artış $(p=0,03, r=0,33)$ bulunurken, femur boynu kemik mineral yoğunluğu $(p=0,009, r=-0,39)$ ve lomber bölgelerin total kemik mineral yoğunluğunda $(p=0,04, r=-0,314)$ anlamlı azalma bulundu. SVK olan (14) ve olmayan (28) hastaların yaş, vücut kitle indeksi, menopoz yaşı, gebelik sayısı, emzirme süresi, sigara kullanımı (paket/yıl), DXA'da lomber bölge, femur boynu ve total kemik mineral yoğunlukları, kalsiyum ve fiziksel aktivite skorları ile kemiğe etkili biyokimyasal belirteçlerin ortalamaları karşılaştırıldığında gruplar arasında yine anlamlı fark bulunmadı $(p>0,05)$ (Tablo 2 ve 3). Hastalarda sekonder osteoporoz saptanmadı.

\section{Tablo 1. Hastaların tanımlayıcı özellikleri.}

$\begin{array}{ll}\text { Yaş ortalaması } & 59,26 \pm 9,19 \\ \text { Cinsiyet } & \text { Kadın: } 31(\% 73,8) \\ & \text { Erkek: } 11(\% 26,2) \\ \text { Osteoporoz } & \text { Var: } 21(\% 50) \\ & \text { Yok: } 21(\% 50) \\ \text { Vücut kitle indeksi }\left(\mathrm{kg} / \mathrm{m}^{2}\right) & 26,33 \pm 3,21 \\ \text { Subklinik vertebral kırık } & \text { Var: } 14(\% 33,3) \\ & \text { Yok: } 28(\% 66,7) \\ \text { Fiziksel aktivite skoru } & 12,43 \pm 5,31 \\ \text { Kalsiyum alım skoru } & 9,65 \pm 3,34\end{array}$

Tablo 2. SVK varlığını etkileyen faktörlerin ortalamalarının karşılaştırıması.

\begin{tabular}{|llll|}
\hline Özellik & SVK var $(\mathrm{n}=14)$ & SVK yok $(\mathrm{n}=28)$ & $\mathrm{p}$ \\
\hline Yaş $(\mathrm{yll})$ & $62,78 \pm 8,90$ & $57,14 \pm 8,94$ & 0,06 \\
VKI $\left(\mathrm{kg} / \mathrm{m}^{2}\right)$ & $25,73 \pm 3,66$ & $26,47 \pm 2,91$ & 0,48 \\
Menopoz yaşı (yıl) & $44,50 \pm 6,07(\mathrm{~N}=8)$ & $44,35 \pm, 7,51(\mathrm{~N}=20)$ & 0,96 \\
Gebelik sayısı & $4,33 \pm 3,60(\mathrm{~N}=9)$ & $4.09 \pm 2,06(\mathrm{~N}=22)$ & 0,81 \\
Emzirme süresi (ay) & $26,81 \pm 31,19(\mathrm{~N}=8)$ & $19,50 \pm 22,86(\mathrm{~N}=21)$ & 0,49 \\
Sigara (paket/yll) & $7,90 \pm 14,65(\mathrm{~N}=8)$ & $12,58 \pm 12,25(\mathrm{~N}=15)$ & 0,42 \\
Lomber KMY & $0,91 \pm 0,18$ & $0,96 \pm 0,14$ & 0,21 \\
Femur boyun KMY & $0,75 \pm 0,09$ & $0,81 \pm 0,10$ & 0,12 \\
Toplam KMY & $0,79 \pm 0,12$ & $0,85 \pm 0,09$ & 0,09 \\
Lomber T-skor & $-2,35 \pm 1,47$ & $-1,75 \pm 1,24$ & 0,18 \\
Femur boyun T-skor & $-2,11 \pm 0,78$ & $-1,63 \pm 0,88$ & 0,09 \\
Toplam T-skor & $-1,77 \pm 1,02$ & $-1,26 \pm 0,82$ & 0,09 \\
Fiziksel aktivite skoru & $13,64 \pm 6,09$ & $11,69 \pm 4,91$ & 0,27 \\
Kalsiyum alım skoru & $9,00 \pm 2,18$ & $9,96 \pm 3,87$ & 0,39 \\
\hline VKi: Vücut kitle indeksi, KMY: Kemik mineral yoğunluğu, SVK: Subklinik vertabral kirk & & \\
\hline
\end{tabular}




\begin{tabular}{|llll|}
\hline Test & SVK var $(\mathrm{n}=14)$ & SVK yok $(\mathrm{n}=\mathbf{2 8})$ & $\mathbf{p}$ \\
\hline B $12(\mathrm{pg} / \mathrm{ml})$ & $426,92 \pm 264,16$ & $349,52 \pm 209,91$ & 0,32 \\
Folat $(\mathrm{ng} / \mathrm{ml})$ & $11,52 \pm 6,53$ & $8,96 \pm 3,71$ & 0,12 \\
Homosistein $(\mu \mathrm{mol} / \mathrm{l})$ & $10,96 \pm 3,36$ & $17,42 \pm 14,38$ & 0,12 \\
D vitamini $(\mathrm{nmol} / \mathrm{l})$ & $59,35 \pm 29,33$ & $60,42 \pm 28,33$ & 0,91 \\
Osteokalsin $(\mathrm{ng} / \mathrm{ml})$ & $8,97 \pm 4,50$ & $11,47 \pm 5,36$ & 0,15 \\
Deoksipridinolin $(\mathrm{pmol} / \mu \mathrm{mol})$ & $8,10 \pm 2,81$ & $8,66 \pm 2,67$ & 0,54 \\
Alkalen fosfataz $(\mathrm{U} / \mathrm{l})$ & $78,42 \pm 28,13$ & $81,11 \pm 19,46$ & 0,72 \\
Kalsiyum $(\mathrm{mg} / \mathrm{dl})$ & $9,35 \pm 0,40$ & $9,33 \pm 0,44$ & 0,87 \\
Fosfor $(\mathrm{mg} / \mathrm{dl})$ & $3,67 \pm 0,60$ & $3,60 \pm 0,54$ & 0,69 \\
Parathormon $(\mathrm{pg} / \mathrm{ml})$ & $59,75 \pm 53,47$ & $64,38 \pm 43,65$ & 0,76 \\
Idrarda kalsiyum (mg/gün) & $166,92 \pm 82,49$ & $127,72 \pm 101,70$ \\
\hline
\end{tabular}

\section{Tartışma}

Osteoporoz özürlülüğe neden olabilen yaygın bir hastalıktır ve klinik anlamlıı̆̆ı kırık oluşumudur. Osteoporozun yol açtığı kırıklar düşük enerjili travmalar sonucunda oluşan ve belirli bölgelerde gelişme eğilimi gösteren kırıklardır. En sık kırıklar vertebrada görülmektedir. Morfometrik kırıkların yaklaşık \%30’u klinik olarak belirgin olduğundan, vertebra kırığı prevelansını tespit etmek oldukça güçtür (11). İkinci en yaygın osteoporotik kırık kalça kırıklarıdır. Üçüncü en yaygın osteoporotik kırık distal ön kol kırıklarıdır. Özellikle bu kırıklar diğer frajilite kırıklarından yirmi yıl kadar önce oluşabilmekte ve hekimi bu konuda uyarması gereken kırıklar olarak rol oynamaktadır (12).

Ön kol kırıkları kadınlarda yaş ile birlikte doğrusal olarak artmaktadır, fakat erkeklerde oldukça sabit bir insidansa sahiptir. Kadınlarda oransal olarak 50'li yaşlarda erkeklerde $60^{\prime}$ lı yaşlarda artış göstermektedir $(13,14)$. Bizim çalışmamızda da benzer şekilde kadınların RDUK geliştiği zamanki yaş ortalaması 56,65 erkeklerin yaş ortalaması ise 62,36 idi. Bazı çalışmalarda RDUK olan kişilerde sağlıkı kontrollerine göre kemik mineral yoğunluğu daha az bulunmuştur (15-17). Çalışmamızda kontrol grubumuz olmasa da DXA'da osteoporoz oranı \%50 (21) olarak bulunurken, osteopeni oranı ise $\% 35,7$ (15) olarak benzer şekilde yüksek oranda saptanmıştır.

Osteoporoz kırıklarla komplike oluncaya kadar sessiz bir hastalıktır. İlk kırık geliştikten sonra etkin tedavi gelecekte oluşacak kırık riskini azaltır. Amerika Ulusal Osteoporoz Vakfı-National Osteoporosis Foundation (NOF)'na göre düşük enerjili kırık öyküsü olanlara, 50 yaşından sonra kırığı olanlara DXA ölçüm endikasyonu vardır. Kanada konsensusında ise 40 yaşından sonra frajilite kırı̆̆ı geçirmek DXA endikasyonudur. Osteoporoza ait klinik risk faktörlerinin sorgulanmasının yanısıra, kemik mineral yoğunluk ölçümü ile torakal lomber vertebra grafilerinin çekilmesi de önerilmektedir. NOF'a göre DXA'da osteopeni varlığında FRAX (Kırık riski değerlendirme aracı= Fracture Risk Asessment Tool) ile 10 yıllık kalça kırık riski $\geq \% 3$ veya major osteoporotik kırık (humerus, ön kol, klinik vertebra kırığı) riski $\geq \% 20$ ise tedavi önerilmektedir $(28,29)$. RDUK geçirmiş 147 kadın hastanın alındığı bir çalışmada bu hastaların hiçbirinin acil servisten çıkış sonrası DXA veya grafi için yönlendirilmediği bildirilmiştir. Bu hastalara ulaşılıp DXA çektirildiğinde, \%24 (79)'unda osteoporoz tespit edildiği bildirilmiştir (18). Çalışma grubumuzdaki hastalara da benzer şekilde DXA ile dorsal ve lomber vertebral grafi çekimi acil servis çıkışı sonrasında önerilmemişti. Birçok çalışmada kalça ve vertebra kırık riskinin daha önce geçirilmiş ön kol kırığı olan kişilerde anlamlı olarak artmış olduğu bildirilmiştir (19-21). Düşük enerjili ön kol ve vertebral kırık geçirmiş kişilerin alındığı bir metaanalizde kalça kırığı riskinin rölatif olarak 1,53 ve 2,20 kat arttığı ve yaş ilerledikçe bu riskin 3,26 ve 3,54 olarak arttığı bildirilmiştir (22). Toplum bazlı bir çalışmada 175 sağlıklı postmenopozal kadından 20'sinde vertebral kırık ve yedisinde RDUK saptanmıştır. Vertebral kırık saptanan hastalarda kemik mineral yoğunluğu başlangıçta normal saptanmış, RDUK saptananlarda ise başlangıç kemik mineral yoğunluğu düşük saptanmıştır. İzlemde her iki hasta grubu için kemik mineral yoğunluğunun azaldığı gözlenmiştir (23). Hastalarımızda SVK oranı \%33,3 (14) yüksek olarak saptanmıştır. SVK'sı olan hastalarımızda kemik mineral yoğunluğu daha düşük olsa da osteoporoz varlığı ile SVK varlığı arasında anlamlı korelasyon bulunamamıştır. Bu durum hasta sayısının az olması ile ilişkili olabilir. Ayrıca yapılan biyokimyasal incelemeler sonucunda bu hastaların hiçbirinde sekonder osteoporoz nedeni saptanamamıştır. Ancak hasta grubumuzda SVK sayısının yaş ile artmış olduğu gözlenmiştir. Vertebral kırıklar asemptomatik olabilmektedirler. Oysa ki sonradan gelişebilecek yeni kırıkların önemli belirleyicisidirler ve bu oran \%8-13 arasında bildirilmektedir (24). Bu anlamda çalışmamız da önem taşımaktadır.

Bu çalışmada RDUK'lı hastalarımızda osteoporoz, SVK oranı ve bu duruma etkili diğer faktörleri araştırmayı amaçladık. Bu hastaların RDUK üzerinden uzun süre geçmesine rağmen yeterince osteoporoz açısından değerlendirilmediğini gördük. Hasta sayısı az olması ve kontrol grubumuzun olmaması ise çalışmamızın kısıtlılıklarıdır.

Sonuç olarak; RDUK'lar toplumda sık görülen kırıklar olup, osteoporoz açısından bu kırıkları olan hastaların değerlendirilmeleri önem taşımaktadır. Düşük enerjili RDUK geçiren hastalarda DXA ile osteoporoz saptanmasa da SVK mevcut olabilir. Bu nedenle bu grup hastalar gerek osteoporoz, gerekse SVK açısından çok iyi değerlendirilmeli ve gerekli önlemler ve tedaviler açısından geç kalınmamalıdır. 


\section{Çıkar Çatışması:}

Yazarlar herhangi bir çıkar çatışması bildirmemişlerdir.

\section{Kaynaklar}

1. Dawson-Hughes B. Prevention. In: Riggs BL, Melton III LJ (eds) Osteoporosis: Etiology, Diagnosis, and Management. 2nd ed.Philadelphia; Lippincott-Raven: 1995. p. 335-50.

2. Gür $S$, Kemik kalitesi ve kırık ilişkisi, Gökçe-Kutsal $Y$ editor. Osteoporozda kemik kalitesi. Güneş Kitabevi, 2004. s. 235.

3. Endres HG, Dasch B, Maier C, Lungenhausen M, Smektala $R$, Trampisch HJ, et al. Diagnosis and treatment of osteoporosis in postmenopausal women with distal radius fracture in Germany. Curr Med Res Opin 2007;23:2171-81.

4. Haentjens P, Johnell O, Kanis JA, Bouillon R, Cooper C, Lamraski G, et al. Evidence From Data Searches and Life-Table Analyses for GenderRelated Differences in Absolute Risk of Hip Fracture After Colles' or Spine Fracture: Colles' Fracture as an Early and Sensitive Marker of Skeletal Fragility in White Men. J Bone Miner Res 2004;19:1933-44.

5. Kurup HV, Andrew JG. Secondary prevention of osteoporosis after Colles fracture: Current practice. Joint Bone Spine 2008;75:50-2.

6. Hollevoet $N$, Verdonk R. Outcome of distal radius fractures in relation to bone mineral density. Acta Orthop Belg 2003;69:510-4.

7- Silman AJ. Risk factors for Colles' fracture in men and women: results from the European Prospective Osteoporosis Study. Osteoporos Int 2003:14:213-8.

8. Nordvall H, Glanberg-Persson G, Lysholm J. Are distal radius fractures due to fragility or to falls? A consecutive case-control study of bone mineral density, tendency to fall, risk factors for osteoporosis, and health-related quality of life. Acta Orthop 2007;78:271-7.

9. Bahari S, Morris S, Lenehan B, McElwain JP. Osteoporosis and orthopods" incidences of osteoporosis in distal radius fracture from low energy trauma.Injury. 2007;38:759-62.

10. Ross PD, Davis JW, Epstein RS, Wasnich RD. Pre-existing fractures and bone mass predict vertebral fracture incidence in women. Ann Intern Med 1991;114:919-23.

11. Burge R, Dawson-Hughes B, Solomon DH, Wong JB, King A, Tosteson A. Incidence and economic burden of osteoporosis-related fractures in the United States, 2005-2025. | Bone Miner Res 2007:22:465-75.

12. Robinson CM, Royds M, Abraham A, McQueen MM, Court-Brown CM, Christie I. Refractures in patients at least forty five yearsold, a prospective analysis of twenty two thousand and sixty patients. J Bone Joint Surg Am 2002;84:1528-33.

13. Cooper C, Melton LJ III. Epidemiology of osteoporosis. Trends Endocrinol Metab 1992;3:224-9.

14. Holroyd C, Cooper C, Dennison E. Epidemiology of osteoporosis. Best Pract Res Clin Endocrinol Metab 2008;22:671-85.
15. Owen RA, Melton LI 3rd, Ilstrup DM, Johnson KA, Riggs BL. Colles' fracture and subsequent hip fracture risk. Clin Orthop Relat Res 1982;171:37-43.

16. Cuddihy MT, Gabriel SE, Crowson CS, O'Fallon WM, Melton LI 3rd. Forearm fractures as predictors of subsequent osteoporotic fractures. Osteoporosis Int 1999;9:469-75.

17. Mallmin H, Ljunghall S, Persson I, Naessén T, Krusemo UB, Bergström R. Fracture of the distal forearm as a forecaster of subsequent hip fracture: a population- based cohort study with 24 years of follow up. Calcif Tissue Int 1993:52:269-72.

18. Rud B, Greibe R, Hyldstrup L, Sørensen HA. Does a distal forearm fracture lead to evaluation for osteoporosis? A retrospective cohort study in 147 Danish women. J Clin Densitom 2005;8:18-24.

19. Mallmin $\mathrm{H}$, Ljunghall $\mathrm{S}$. Distal radius fracture is an early sign of general osteoporosis :bone mass measurements in a population - based study. Osteoporosis Int 1994:4:357-61.

20. Peel NF, Barrington NA, Smith TW, Eastell R. Distal forearm fracture risk factor for vertebral osteoporosis. Br Med J 1994;308:1543-4.

21. Masud T, Jordan D, Hosking D. Distal forearm fracture history in an older community - dwelling population: The Nottingham Community Osteoporosis (NOCOS) Study. Age Ageing 2001:30;255-8.

22. Haentjens $P$, Autier $P$, Collins J, Velkeniers B, Vanderschueren D, Boonen $S$. Colles fracture, spine fracture, and subsequent risk of hip fracture in men and women. A meta-analysis. J Bone Joint Surg Am 2003;85:1936-43.

23. Hansen MA, Overgaard K, Riis BJ, C Christiansen. Role of peak bone mass and bone loss in postmenopausal osteoporosis: 12 year study. BMJ 1991;303:961-64.

24. Lindsay R, Silverman SL, Cooper C, Hanley DA, Barton I, Broy SB, et al. Risk of new vertebral fracture in a year following fracture. JAMA 2001;285:320-3.

25. O'Neil TW, Cooper C, et al. Design and development of a questionnaire for use in a multicentre study of vertebral osteoporosis study (EVOS). Rheumatology Europe 1995;24:75-81.

26. O'Neill TW, Cooper C, Cannata JB, Diaz Lopez JB, Hoszowski K, Johnell $\mathrm{O}$, et al. Reproducibility of a questionnaire on risk factors for osteoporosis in a multicentre prevelance survey: The European Vertebral Osteoporosis Study. Int I Epidemiol 1994:23:555-65.

27. Genant HK, Wu CY, van Kuijk C, Nevitt MC. Vertebral fracture assessment using a semiquantitative technique. J Bone Miner Res 1993;8:1137-48.

28. Physician's guide to prevention and treatment of osteoporosis. National Osteoporosis Foundation, 2000, Washington DC.

29. Dawson-Hughes B, Tosteson AN, Melton LI 3rd, Baim S, Favus MJ, Khosla $S$, et al. Implications of absolute fracture risk assessment for osteoporosis practice guidelines in the USA. Osteoporos Int 2008;19:449-58. 